This is the author's final, peer-reviewed manuscript as accepted for publication. The publisher-formatted version may be available through the publisher's web site or your institution's library.

\title{
A lipidomic approach to identify cold-induced changes in Arabidopsis membrane lipid composition
}

Hieu Sy Vu, Sunitha Shiva, Aaron Smalter Hall, and Ruth Welti

\section{How to cite this manuscript}

If you make reference to this version of the manuscript, use the following information:

Vu, H. S., Shiva, S., Hall, A. S., \& Welti, R. (2014). A lipidomic approach to identify coldinduced changes in Arabidopsis membrane lipid composition. Retrieved from http://krex.ksu.edu

\section{Published Version Information}

Citation: Vu, H. S., Shiva, S., Hall, A. S., \& Welti, R. (2014). A lipidomic approach to identify cold-induced changes in Arabidopsis membrane lipid composition. In D. K. Hincha \& E. Zuther (Eds.), Plant Cold Acclimation: Methods and Protocols, Methods in Molecular Biology, 1166, 199-215.

Copyright: @ Springer Science+Business Media New York 2014

Digital Object Identifier (DOI): doi:10.1007/978-1-4939-0844-8_15

Publisher's Link: http://link.springer.com/protocol/10.1007\%2F978-1-4939-0844-8_15

This item was retrieved from the K-State Research Exchange (K-REx), the institutional repository of Kansas State University. K-REx is available at http://krex.ksu.edu 


\section{A lipidomic approach to identify cold-induced changes in Arabidopsis membrane lipid composition}

Hieu Sy Vu ${ }^{1}$, Sunitha Shiva ${ }^{1}$, Aaron Smalter Hall ${ }^{2}$, and Ruth Welti ${ }^{1 *}$

${ }^{1}$ Kansas Lipidomics Research Center, Division of Biology, Ackert Hall, Kansas State University, Manhattan, KS 66506, USA

${ }^{2}$ K-INBRE Bioinformatics Core Facility, Structural Biology Center, University of Kansas, Lawrence, KS 66045

*Corresponding author:

Kansas Lipidomics Research Center

Division of Biology

Ackert Hall

Kansas State University

Manhattan, KS 66506, USA

Phone: 785-532-6241

Email: welti@ksu.edu 


\section{Summary}

Lipidomic analysis using electrospray ionization triple quadrupole mass spectrometry can be employed to monitor lipid changes that occur during cold and freezing stress of plants. Here we describe the analysis of Arabidopsis thaliana polar glycerolipids with normal and oxidized acyl chains, sampled during cold and freezing treatments. Mass spectral data are processed using the online capabilities of LipidomeDB Data Calculation Environment.

\section{Key words}

Cold acclimation, Freezing, Post-freezing recovery, Lipidomics, Galactolipid, Phospholipid, Oxidized lipid, Triple quadrupole, Mass spectrometry 


\section{Introduction}

Cold and freezing stress can cause major crop losses. Arabidopsis thaliana can be employed as an experimental model for analysis of the biochemical changes that accompany the development of plant freezing tolerance by cold acclimation and the changes that occur in cold and freezing stress and during plant recovery from freezing stress. Cold acclimation, or the development of tolerance to freezing by exposure to cold, but non-freezing, temperature, is a capability of many plants originating in temperate climates. Cold acclimation of Arabidopsis (Columbia accession) for 1 day or more decreases the lethal temperature from approximately $-2^{\circ} \mathrm{C}$ to $-8^{\circ} \mathrm{C}(1,2)$.

Lipid changes occur during cold acclimation, during the freezing process, and during recovery from freezing stress (e.g., 2-5). One effect of lipid alterations in cold acclimation is to curb lipid phase changes that lead to membrane leakage (2). Indeed, alterations in plant lipid metabolism before or during cold and freezing stress can modulate plant damage (2-5). For example, fatty acid desaturases, such as Ads-2, act to increase fatty acid unsaturation during cold acclimation and have a positive effect on freezing tolerance (6). Desaturases forming trienoic fatty acids also are required for effective photosynthesis at low temperature (7). Generally, acyl lipid levels increase during cold acclimation; indeed, fatty acid synthesis is critical for avoiding plant damage in low temperature stress $(2,3,8)$. The freezing-activated galactolipid:galactosyltransferase encoded by SENSITIVE TO FREEZING 2 (SFR2) forms oligogalatosyldiacylglycerols and also has a positive effect on survival (9). Two phospholipase Ds, which hydrolyze phospholipids, act during freezing and post-freezing recovery, but one increases and the other decreases plant damage during the freezing and post-freezing recovery processes $(3,4,10)$. Cold- or freezing-induced lipid changes may alter binding of lipids to proteins, which may affect protein function and plant stress damage (11). 
There is still much to be discovered about the role of lipids, lipid-metabolizing enzymes, and lipidbinding proteins in cold and freezing stress. Mass spectrometry-based lipidomics offers many advantages in monitoring cold- and freezing induced lipid changes. A lipidomic method can be used to examine a large number of lipid molecular species and to perform the analysis in a relatively short time. Lipid extracts from cold-treated plants may be introduced to a mass spectrometer by direct infusion or by liquid chromatography, and both methods have been utilized in Arabidopsis cold stress studies $(3,12,13)$. Here we describe a direct infusion approach similar to that used to analyze lipids during cold acclimation and freezing stress in recent work by $\mathrm{Vu}$ et al. (13) and extend our previously described analytical approach $(3,14)$. The procedure takes advantage of the automated capability for processing of triple quadrupole mass spectral data at LipidomeDB Data Calculation Environment (15).

The analytical procedure described here measures membrane phospholipids and galactolipids, with identification of mass spectral data in terms of lipid class, total acyl carbons, and total double bonds (i.e. total acyl carbons: total acyl carbon-carbon double bonds). For membrane lipids with normal acyl chains, compound identifications are based on the mass/charge ratio $(\mathrm{m} / \mathrm{z})$ of the intact ion and the mass or $\mathrm{m} / \mathrm{z}$ of one fragment formed in the mass spectrometer. Typically, for polar lipids, this is a head group fragment. In addition, the analysis of phospholipids and galactolipids containing oxidized acyl chains is described; these lipids are specified by head group and acyl species.

Lipid amounts are determined as normalized mass spectral signal/plant dry mass. The intensities of peaks in each sample are compared to those of added internal standards. A value of 1 represents the same intensity as $1 \mathrm{nmol}$ of a relevant internal standard (or an $\mathrm{m} / \mathrm{z}$-corrected intensity of two internal standards detected in the same mass spectral scan). For diacyl or monoacyl phospholipids, the response for each compound is very close (within 5 or 10\%) of the response of an internal standard of the same class. Thus, the normalized signal/dry mass for diacyl or monoacyl phospholipids can be considered to be equal to $\mathrm{nmol} / \mathrm{dry}$ mass. On the other hand, the molar responses of galactolipids and the oxidized membrane 
lipids have not been carefully characterized. In these cases, comparison among samples of the normalized signal/dry mass for the same lipid is valid, but normalized signal/dry mass may not be an accurate indicator of the relative amount of each lipid compared to other lipids in the sample.

The protocol for cold and freezing described herein is for cold and freezing treatment of Arabidopsis thaliana (Columbia accession and accessions with similar freezing tolerance). More details on cold acclimation, freezing, and post-freezing treatments can be found elsewhere in this volume.

\section{Materials (see Note 1)}

\subsection{For cold acclimation, freezing treatment, and sampling}

1. Arabidopsis thaliana plants, grown in a growth chamber and in soil, such as Pro-Mix "PGX" (Hummert International, 10-2022-1), in 31/2” Kord square pots (Hummert International, 12-13501) or 72-cell plug trays (International Greenhouse Company, CN-PRT 72) (see Note 2.)

2. Light meter

3. Waxed paper, scissors

4. Ice chips

5. Growth chamber, such as a Conviron ATC26

6. Walk-in cold room

7. Light cart (Hummert International, 65-6924-1)

8. Freezing chamber

\subsection{For sampling, lipid extraction, and dry mass measurement}

1. Scissors

2. Isopropanol with $0.01 \% \mathrm{BHT}(\mathrm{w} / \mathrm{v})$

3. HPLC-grade chloroform 
4. HPLC-grade water

5. Chloroform/methanol $(2: 1, \mathrm{v} / \mathrm{v})$ with $0.01 \% \mathrm{BHT}(\mathrm{w} / \mathrm{v})$

6. $\mathrm{KCl}, 1 \mathrm{M}$ in water

7. Glass tubes, $50 \mathrm{~mL}(25 \times 150 \mathrm{~mm})$ with Teflon-lined screw caps (Fisher, 14-930-10J)

8. Pasteur pipettes, 9-inch

9. Dry block heater that accepts $50 \mathrm{~mL}$ tubes

10. Vortex mixer

11. Orbital shaker

12. Vacuum concentrator (such as CentriVap), vented to hood, or nitrogen gas stream evaporator, in hood

13. Low-speed (clinical-type) centrifuge

14. Oven, vented to hood

15. Balance that determines mass, preferably to micrograms

16. Ionizer antistatic system (VWR, 11238-356) (see Note 3).

\subsection{For mass spectrometry}

1. Methanol/300 $\mathrm{mM}$ ammonium acetate in water $(95: 5, \mathrm{v} / \mathrm{v})$

2. Chloroform

3. Internal standard mix, containing LPC(13:0) (see Note 4), LPE(14:0), LPE(18:0), PA(28:0)

[di14:0], PA(40:0) [diphytanoyl], PA(40:0) [diphytanoyl], PC(24:0) [di12:0], PC(48:2) [di 24:1], PE(24:0) [di12:0], PE(46:0) [di23:0], PG(28:0) [di14:0], PG(40:0) [diphytanoyl], hydrogenated PI, PS(28:0) [di14:0], PS(40:0) [diphytanoyl], hydrogenated DGDG, and hydrogenated MGDG (14) (see Note 5).

4. Pre-slit, target Snap-it $11 \mathrm{~mm}$ Snap Caps (MicroLiter, 11-0054DB)

5. Amber vials, $12 \times 32 \mathrm{~mm}$ (MicroLiter, 11-6200)

6. Autosampler, such as CTC Mini-PAL (LEAP), with $1 \mathrm{~mL}$ sample loop 
7. Sample trays to hold vials, such as VT54 (LEAP)

8. Large reservoir (e.g. $500 \mathrm{~mL}$ ) syringe pump with pump controller to provide continuous infusion. Reservoir is filled with methanol or methanol:isopropanol $(1: 1, \mathrm{v} / \mathrm{v})$

9. Methanol/acetic acid $(9: 1, \mathrm{v} / \mathrm{v})$ for washing between samples

10. Methanol/chloroform/water $(66.5: 30: 3.5, \mathrm{v} / \mathrm{v} / \mathrm{v})$ to fill the wash reservoirs on the autosampler for washing the syringe and sample loop

11. Triple quadrupole mass spectrometer, such as API 4000 (Applied Biosystems, Foster City, CA), with electrospray ionization source

\section{Methods}

\subsection{Cold-acclimation, freezing treatment, and sampling}

1. Transfer soil-grown Arabidopsis plants to the portable light cart. Put the light cart into cold room with desired temperature $\left(1\right.$ to $\left.4{ }^{\circ} \mathrm{C}\right)$ for cold acclimation. Light intensity and day/night cycle should be measured with a light meter and adjusted to match those of the growing condition.

2. Acclimate plants by placing in the cold room for the desired period (0 to 7 days).

3. For plants that will undergo freezing, cut pieces of waxed paper to cover half of soil around each plant. Gently place waxed paper under Arabidopsis rosettes and on top of soil as shown in Figure 1.

4. Transfer plants to be frozen to the programmable freezing chamber. Program the freezing chamber so that the temperature drops from the cold acclimation point to $-2{ }^{\circ} \mathrm{C}$ at $2{ }^{\circ} \mathrm{C}$ per hour (see Note 6). Plants may be held at $-2{ }^{\circ} \mathrm{C}$ for $1 \mathrm{~h}$ for ice crystal formation before the temperature is dropped at $-2{ }^{\circ} \mathrm{C}$ to the final temperature. Ice chips may be added on soil (under or around waxed paper) at this step to prevent supercooling (see Note 7).

5. After the freezing treatment (typically $2 \mathrm{~h}$ ), plants may be thawed at $4{ }^{\circ} \mathrm{C}$ or other desired temperature (see Note 8). 


\subsection{Sampling, lipid extraction, and dry mass measurement}

The method is modified from reference 16. Additional recommendations and options for extraction have been provided previously in another article in this series (14).

1. Plants may be sampled at desired time points before cold acclimation, during acclimation, after freezing or during a post-freezing recovery period (see Note 9). Cut leaves, rosettes, or other desired tissue and quickly submerge plant tissues in isopropanol (containing $0.01 \%$ BHT) at 75 ${ }^{\circ} \mathrm{C}$ for $15 \min ($ see Note 10$)$.

2. For plant tissues with dry mass less than $30 \mathrm{mg}$, submerge in $50-\mathrm{ml}$ glass tube containing $3 \mathrm{ml}$ of isopropanol (0.01\% BHT), add $1.5 \mathrm{ml}$ chloroform and $0.6 \mathrm{ml}$ water (see Note 11).

3. Shake the tube at $100 \mathrm{rpm}$ for $1 \mathrm{~h}$ at room temperature. Transfer solvent to a different tube.

4. Add $4 \mathrm{ml}$ of chloroform: methanol $(2: 1, \mathrm{v} / \mathrm{v})$ to the tissues in the first tube. Shake for $30 \mathrm{~min}$ and transfer solvent to the same tube used in step 2.

5. Repeat step 3 three additional times. Combine all extracts (see Note 12).

6. Evaporate the combined extract with a nitrogen stream or vacuum concentrator (i.e., centrifuging evaporator; CentriVap).

7. Dissolve lipids in $1 \mathrm{ml}$ of chloroform and store at $-20^{\circ} \mathrm{C}$ or colder.

8. Extracted tissues should be dried overnight at $105^{\circ} \mathrm{C}$ and cooled. The dry mass should be determined using the microgram balance.

\subsection{Mass spectrometry}

1. Add $10 \mu \mathrm{l}$ of internal standard mix to each $2-\mathrm{ml}$ amber glass vial. From $1 \mathrm{ml}$ of sample in chloroform, add a volume originating from $0.2 \mathrm{mg}$ dry tissue mass. Bring the volume to $360 \mu \mathrm{l}$ with chloroform. Add $840 \mu 1$ of the mixture methanol/300 mM ammonium acetate in water (95:5, $\mathrm{v} / \mathrm{v}$ ). The final solvent composition should be chloroform/methanol/300 $\mathrm{mM}$ ammonium acetate in water (30: 66.5: 3.5, v/v/v) (see Note 13). 
2. Make "standards-only" ("i.s.", internal standard) samples with $10 \mu 1$ internal standard mix, $350 \mu 1$ chloroform, and $840 \mu 1$ methanol: $300 \mathrm{mM}$ ammonium acetate in water (95: 5, v/v) (see Note 14).

3. Make a set of washing blank ("wb") vials (equal to number of sample vials) containing methanol: acetic acid (9: 1, v/v) to wash the tubing and ion source system between samples (see Note 15).

4. On a VT-54 sample tray, arrange vials in order: wb, i.s.1, wb, sample1, wb, sample 2, wb, ...sample 9, wb, sample10, wb, i.s.2, wb, ... That is, a washing blank should be every other vial. "Standards-only" samples should be in the spot of a sample and should run after every 10 samples.

5. Program pump, auto-sampler, and mass spectrometer to infuse each sample at $30 \mu 1 / \mathrm{min}$ and acquire a combination of spectra using the parameters shown in Table 1. Use the multiple channel analyzer (MCA) feature and a scan speed between 50 - 100 mass unit per s (see Note 16).

6. After data acquisition, perform baseline subtraction, smoothing, peak integration (centroiding) of the resulted spectra in mass spectrometer software.

7. Export these processed spectral data into Excel files in the format specified at LipidomeDB Data Calculation Environment (DCE) at http://lipidome.bcf.ku.edu:9000/Lipidomics/.

8. Use LipidomeDB Data Calculation Environment (DCE) at http://lipidome.bcf.ku.edu:9000/Lipidomics/ for identification and quantification of lipids (detailed instruction is available at the website). See Tables 1 and 2 for Target Compound Lists, which are provided as preformulated lists in the DCE. Internal standards for normal-chain diacyl lipids are the two internal standards of the same class. The mass spectral signals for the compounds listed in Table 2 can be quantified in relation to MGDG(34:0), which is measured in the -Pre 283.2 scan (see Note 17). For normal-chain phospholipids, results produced by DCE can be interpreted as nmol of target compounds in the analyzed vial. For normal chain galactolipids, oxidized lipids, and acylated lipids, results produced by DCE are intensities normalized to the internal standard(s). A normalized intensity of 1 is the same mass spectral signal as $1 \mathrm{nmol}$ of internal standard (see Note 18). 
9. Normalize amounts of lipid analyzed (nmol, for normal chain phospholipids; normalized signal, for normal chain galactolipids, oxidized and acylated lipids) to mg of dry tissue mass, using this formula: dry-mass-normalized amount $(\mathrm{nmol} / \mathrm{mg}$ or normalized signal $/ \mathrm{mg})=$ $\frac{V t(\mathrm{ml}) \times \text { amount }(\mathrm{nmol} \text { or normalized signal })}{V a(\mathrm{ml}) \times \text { dry mass }(\mathrm{mg})}$, where $\mathrm{Vt}$ is total original sample volume $(1 \mathrm{ml})$; Va is analyzed volume (volume equivalent to the $0.2 \mathrm{mg}$ dry mass that was used in step 1).

\section{Notes}

1. Many of the materials indicated here are the same as listed in reference 14. The methods extend those described in reference 14 and apply them to the analysis of lipids derived from cold and freezing experiments. Portions of the Materials and Methods sections and Table 1 are republished by permission (Springer license number 3207410145743).

2. We typically use 27-day-old Arabidopsis plants, from which we sample rosettes. However, plants at other developmental stages may be used. The current protocol is appropriate for any above-ground vegetative tissue, flowers, or siliques.

3. Using an antistatic system with a microgram-accurate balance (Mettler Toledo) will increase the stability of mass measurements.

4. Abbreviations are: DGDG, digalactosyldiacylglycerol; LPC, lysophosphatidylcholine; LPE, lysophosphatidylethanolamine; LPG, lysophosphatidylglycerol; MGDG, monogalactosyldiacylglycerol; PA, phosphatidic acid; PC, phosphatidylcholine; PE, phosphatidylethanolamine; PG, phosphatidylglycerol; PI; phosphatidylinositol; PS, phosphatidylserine.

5. From $5 \mathrm{mM}$ lipid stock solutions in chloroform or appropriate mixtures of chloroform, methanol, and water (14), mix $120 \mu \mathrm{L}(600 \mathrm{nmol})$ of each LPC and PC; $60 \mu \mathrm{L}$ (300 nmol) of each LPE, PA, PE, and PG; $80 \mu \mathrm{L}$ (400 nmol) of PI; $40 \mu \mathrm{L}$ (200 nmol) of each PS; $240 \mu \mathrm{L}(1,200 \mathrm{nmol})$ of DGDG; and $480 \mu \mathrm{L}(2,400 \mathrm{nmol})$ of MGDG. Bring this mixture to $10 \mathrm{~mL}$ by adding $8.16 \mathrm{~mL}$ 
chloroform. This produces $10 \mu \mathrm{L}$ of a stock solution with $0.6 \mathrm{nmol}$ of each LPC and PC, $0.3 \mathrm{nmol}$ of each LPE, PA, PE, and PG, $0.4 \mathrm{nmol}$ of total PI, $0.2 \mathrm{nmol}$ of each PS; $1.2 \mathrm{nmol}$ of total DGDG, and $2.4 \mathrm{nmol}$ of total MGDG. It's best to determine the concentration of phospholipids for the stock solution by phosphate assay (17). Concentrations of the total MGDG and individual MGDGs (i.e., MGDG(34:0) and MGDG(36:0)), total DGDG and individual DGDGs (i.e., DGDG(34:0) and DGDG(36:0)), and individual PIs (i.e., PI(34:0) and PI(36:0)) are best determined by gas chromatography of fatty acid methyl esters derived from these lipids.

6. Although going directly to the low freezing temperature directly may not perfectly mimic natural freezing, a freezing regimen without gradual temperature change can be employed. If plants are to be placed directly at the low freezing temperature, ice chips can be added right before placing the plants in the freezing chamber.

7. For any freezing regimen, soil should be saturated with water prior to adding of ice chips. An alternative approach to placing ice chips on the soil is to partly submerge the $3 \frac{1}{2}$ " square pots or the $72-w e l l$ plug tray in an ice slurry.

8. Plants may be thawed at $4{ }^{\circ} \mathrm{C}$ or at the growing temperature. Although plants may sustain more damage with recovery at the growing temperature, recovery characteristics of acclimated plants are clearly distinguishable from those of non-acclimated plants (unpublished data).

9. Depending on the particular experimental goal, plants can be sampled early or late in cold acclimation (to measure early or late cold-induced molecular changes), right after freezing treatment (to measure freezing-induced changes), and/or during the recovery phase (to measure thawing-related changes). During the cold acclimation period, it is best to sample inside the cold room, and the temperature of the heating block may need to be closely monitored to maintain 75 ${ }^{\circ} \mathrm{C}$. To sample right after freezing, it is critical to collect the plant tissues quickly without allowing them to thaw. Especially when handling a large number of plants with a reach-in freezing chamber, avoid letting plants wait outside of the chamber; instead, pull out only the number of plants that can be sampled in less than $30 \mathrm{~s}$. Within $30 \mathrm{~s}$, two workers typically can 
sample four Arabidopsis rosettes. If using a 72-well plug tray, the tray can be cut in sections of four plants for sampling by two workers.

10. It is critical to drop harvested leaves into isopropanol at $75{ }^{\circ} \mathrm{C}$ immediately to prevent activation of phospholipase D, a wound-induced enzyme, which will degrade membrane lipids and produce phosphatidic acids.

11. Should a different volume of isopropanol be required (to fully submerge plant tissues when harvesting), the volumes of chloroform and water can be varied accordingly.

12. For Arabidopsis leaves, five rounds of chloroform:methanol extraction are usually sufficient. Leaves should be completely white. For the last extraction, samples may be shaken overnight.

13. $1.2 \mathrm{ml}$ total volume is required when using the indicated amber vial together with the indicated autosampler to ensure complete filling of the 1-ml sample loop without introducing an air bubble. When using a different type of sample vial or a different autosampler, a test filling should be performed to determine optimal total volume.

14. "Standards-only" spectra are used to correct instrument background signal and assess sample carryover. Internal standard peaks in "standards-only" spectra will likely have higher intensities than those in other spectra, because of low ion suppression. Intensities of plant analyte peaks in "standards-only" spectra should be very low, and analyte peak intensities from "standards-only" spectra may be subtracted from the intensities of the same peak from plant lipid spectra to remove background signal in the plant spectra.

15. The "washing blank" has a high concentration of acetic acid to wash the sample loop, the tubing between autosampler and the ion source, and the ion source needle to prevent carryover of acidic lipids such as PA and PS. Right after the sample loop is filled, the sample syringe and the injection port are washed with methanol/chloroform/water $(66.5: 30: 3.5, \mathrm{v} / \mathrm{v} / \mathrm{v})$ contained in the two wash reservoirs of the CTC Mini-PAL autosampler.

16. Parameters, including collision energy, source temperature, source voltages, collision gas pressure, and scanning time should be optimized for each system. It is recommended NOT to use 
the first and the last $1.5 \mathrm{~min}$ of the total run time allowed by the injected volume (i.e., an injected volume of $1000 \mu \mathrm{l}$ allows $\sim 33 \mathrm{~min}$ of run time at flow rate of $30 \mu \mathrm{l} / \mathrm{min}$ ) because of the instability of the ion flow during these periods and because it takes some time (depending on tubing length and diameter) for sample to reach the electrospray source. Instead, for the first $1.5 \mathrm{~min}$, a MS scan for a wide mass range ( $\mathrm{m} / \mathrm{z} 200-800)$ can be acquired and monitored to ensure a continuous ion stream is reaching the detector.

17. On the target list page in LipidomeDB Data Calculation Environment, there is a check box at the top of the page, with the phrase, "Check here is the standards are in a separate spectrum from target compounds." This feature is described in the "advanced users" part of the tutorial. You should not check this box when processing data for normal-chain lipids. You should check this box when processing data for the compounds in Table 2. You will need to load the spectra for the internal standard (the -Pre 283.2 scan) separately from the spectra of the target compounds.

18. Normal chain phospholipids and their internal standards of the same class have very similar response factors (the amount of mass spectral intensity per mol), and this allows accurate quantification of these lipids. On the other hand, the mass spectral response factors of normalchain, oxidized, and acylated galactolipids may differ somewhat from those of their internal standard(s). In particular, for analysis of the compounds listed in Table 2, many compounds differ in structure from the internal standard (MGDG(34:0)).

\section{Acknowledgements}

The authors would like to thank lab members Mary Roth, Pamela Tamura, Thilani Samarakoon, Sam Honey, Drew Roach, and Kaleb Lowe for their contributions to plant stress experiments in our laboratory. This work was funded by National Science Foundation MCB 0920663. Contribution no. 14-036-J from the Kansas Agricultural Experiment Station. 
Figure 1. Arabidopsis plants prepared to undergo freezing. Two half circles of waxed paper have been placed under each rosette. The purpose of the waxed paper is to eliminate freezing of leaves to the soil, which makes it difficult to obtain clean leaf or rosette samples when the plants are frozen.

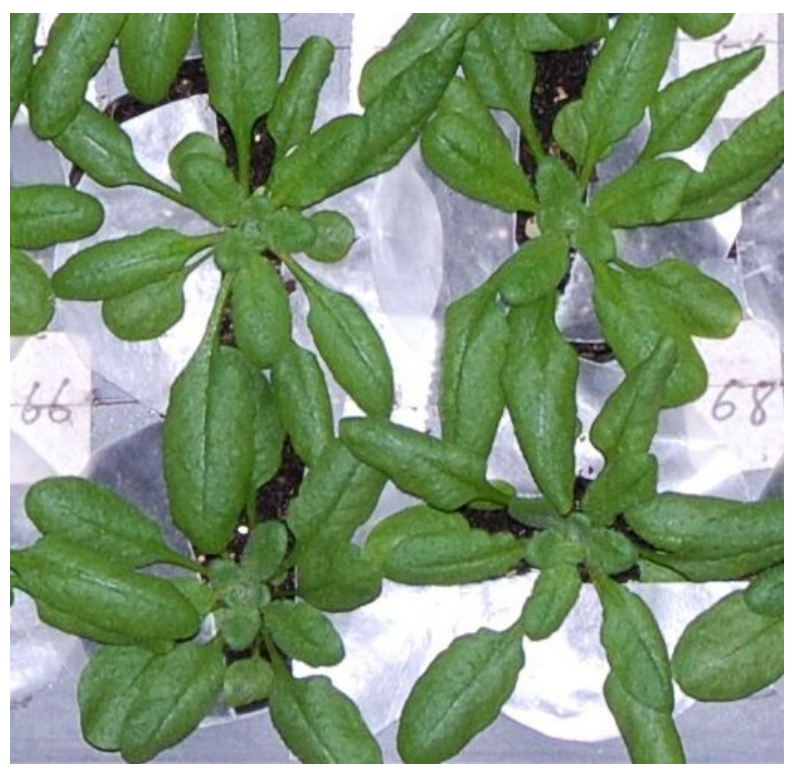




\section{Table 1}

Mass spectral acquisition parameters for analysis of polar plant membrane lipids. The first column, "Class (Target list in DCE) indicates the lipid class and the name of the target lipid list at the online lipidomics data processing site, LipidomeDB Data Calculation Environment. Parameter settings refer to an API 4000 (Applied Biosystems, Foster City, CA) triple quadrupole mass spectrometer with electrospray ionization source. Abbrevations are: DGDG, digalactosyldiacylglycerol; MCA, multiple channel analyzer; MGDG, monogalactosyldiacylglycerol; PA, phosphatidic acid; PC, phosphatidylcholine; PE, phosphatidylethanolamine; PG, phosphatidylglycerol; PI; phosphatidylinositol; PS, phosphatidylserine; acMGDG, acylated monogalactosyldiacylglycerol; ox-, oxidized, i.e. containing an oxidized fatty acyl chain). This table is adapted and expanded from a table in reference 14. (See Note 1.) 


\begin{tabular}{|c|c|c|c|c|c|c|c|c|}
\hline $\begin{array}{c}\text { Class } \\
\text { (Target list } \\
\text { in DCE) } \\
\end{array}$ & Adduct & $\begin{array}{c}\text { Scan mode } \\
(+/-), \text { scan } \\
\text { type, scan } \\
\text { mass } \\
\end{array}$ & $\begin{array}{c}m / z \\
\text { range } \\
\text { scanned }\end{array}$ & $\begin{array}{l}\text { MCA } \\
\text { cycles }\end{array}$ & $\begin{array}{c}\text { Col- } \\
\text { lision } \\
\text { energy } \\
(\mathrm{V}) \\
\end{array}$ & $\begin{array}{c}\text { Depolar- } \\
\text { ization } \\
\text { poten- } \\
\text { tial (V) }\end{array}$ & $\begin{array}{c}\text { Exit } \\
\text { poten- } \\
\text { tial } \\
(\mathrm{V}) \\
\end{array}$ & $\begin{array}{c}\text { Collision } \\
\text { exit } \\
\text { potential } \\
(\mathrm{V})\end{array}$ \\
\hline $\begin{array}{l}\text { DGDG (Plant } \\
\text { DGDG) }\end{array}$ & {$\left[\mathrm{M}+\mathrm{NH}_{4}\right]+$} & $+\mathrm{NL}, 341.13$ & $890-1050$ & 50 & 24 & 90 & 10 & 23 \\
\hline $\begin{array}{l}\text { MGDG (Plant } \\
\text { MGDG) }\end{array}$ & {$\left[\mathrm{M}+\mathrm{NH}_{4}\right]+$} & $+\mathrm{NL}, 179.08$ & $700-900$ & 50 & 21 & 90 & 10 & 23 \\
\hline $\begin{array}{l}\text { PA (Plant } \\
\text { PA) }\end{array}$ & {$\left[\mathrm{M}+\mathrm{NH}_{4}\right]+$} & +NL, 115.00 & $500-800$ & 60 & 25 & 100 & 14 & 14 \\
\hline $\begin{array}{c}\text { PC (Plant } \\
\text { PC), LPC } \\
\text { (Plant LPC) }\end{array}$ & {$[\mathrm{M}+\mathrm{H}]+$} & +Pre, 184.07 & $450-690$ & 20 & 40 & 100 & 14 & 14 \\
\hline $\begin{array}{c}\text { PE (Plant } \\
\text { PE), LPE } \\
\text { (Plant LPE) }\end{array}$ & {$[\mathrm{M}+\mathrm{H}]+$} & +NL, 141.02 & $420-920$ & 50 & 28 & 100 & 15 & 11 \\
\hline $\begin{array}{l}\text { PG (Plant } \\
\text { PG) }\end{array}$ & {$\left[\mathrm{M}+\mathrm{NH}_{4}\right]+$} & +NL, 189.04 & $650-1000$ & 60 & 20 & 100 & 14 & 14 \\
\hline PI (Plant PI) & {$\left[\mathrm{M}+\mathrm{NH}_{4}\right]+$} & $+\mathrm{NL}, 277.06$ & $790-950$ & 150 & 25 & 100 & 14 & 14 \\
\hline PS (Plant PS) & {$[\mathrm{M}+\mathrm{H}]+$} & $+\mathrm{NL}, 185.01$ & $600-920$ & 80 & 26 & 100 & 14 & 14 \\
\hline \multirow{5}{*}{$\begin{array}{c}\text { ox-PC, ox- } \\
\text { PE, ox-PG, } \\
\text { ox-DGDG, } \\
\text { ox-MGDG, } \\
\text { acMGDG, } \\
\text { and ox- } \\
\text { acMGDG } \\
\text { (see Table } 2 \\
\text { for target list) }\end{array}$} & \multirow{5}{*}{ (see Table 2) } & -Pre 277.2 & $\begin{array}{l}1040- \\
1100\end{array}$ & \multirow{5}{*}{65} & \multirow{5}{*}{-45} & \multirow{5}{*}{-100} & \multirow{5}{*}{-10} & \multirow{5}{*}{-20} \\
\hline & & -Pre 283.2 & $815-820$ & & & & & \\
\hline & & -Pre 291.2 & $740-1150$ & & & & & \\
\hline & & -Pre 293.2 & $720-1030$ & & & & & \\
\hline & & -Pre 295.2 & $730-860$ & & & & & \\
\hline
\end{tabular}




\section{Table 2}

\section{Oxidized membrane lipids and acylated MGDG analyzed by the negative precursor scans 277.2,}

291.2, 293.2, and 295.2 and target lists for their analysis. " $M$ mass" and " $M$ formula" indicate the mass and formula of the uncharged lipid; ion $\mathrm{m} / \mathrm{z}$ can be approximated by subtracting 1 from (for $[\mathrm{M}-\mathrm{H}]^{-}$ adduct) or adding 59 to (for $\left[\mathrm{M}+\mathrm{C}_{2} \mathrm{H}_{3} \mathrm{O}_{2}\right]^{-}$adduct) molecular mass (M mass). "Compound designations" include class abbreviation (acMGDG, acylated monogalactosyldiacylglycerol; DGDG, digalactosyldiacylglycerol; MGDG, monogalactosyldiacylglycerol; PC, phosphatidylcholine; PE, phosphatidylethanolamine; PG, phosphatidylglycerol) and, in parentheses, total acyl carbons: total acyl carbon-carbon double bonds. "Scan mode and adduct" indicates the $m / z$ of the negative precursor scan and the detected adduct. Entries with the same "Scan mode and adduct" (i.e. from the same mass spectrum) are listed together and the data are processed together. "Target list in DCE" indicates the title of the target lipid list in the online lipidomics data processing site, LipidomeDB Data Calculation Environment, for data from a particular scan mode. More details on chemical structures of the listed lipids are available in the Supplemental Data of reference 13. The internal standard for these targets is MGDG(34:0), which is analyzed in the -Pre 283.2 scan (Table 1 and text). 


\begin{tabular}{|c|c|c|c|c|}
\hline M mass & M formula & Compound designations & Scan mode and adduct & Target list in DCE \\
\hline 984.6 & $\mathrm{C}_{59} \mathrm{H}_{100} \mathrm{O}_{11}$ & acMGDG(50:6) & -Pre 277.2, $\left[\mathrm{M}+\mathrm{C}_{2} \mathrm{H}_{3} \mathrm{O}_{2}\right]^{-}$ & 18:3-unox-acMGDG-1 \\
\hline 990.6 & $\mathrm{C}_{59} \mathrm{H}_{106} \mathrm{O}_{11}$ & $\operatorname{acMGDG}(50: 3)$ & -Pre 277.2, $\left[\mathrm{M}+\mathrm{C}_{2} \mathrm{H}_{3} \mathrm{O}_{2}\right]^{-}$ & 18:3-unox-acMGDG-1 \\
\hline 1006.6 & $\mathrm{C}_{61} \mathrm{H}_{98} \mathrm{O}_{11}$ & acMGDG(52:9) & -Pre 277.2, $\left[\mathrm{M}+\mathrm{C}_{2} \mathrm{H}_{3} \mathrm{O}_{2}\right]^{-}$ & 18:3-unox-acMGDG-1 \\
\hline 1012.6 & $\mathrm{C}_{61} \mathrm{H}_{104} \mathrm{O}_{11}$ & acMGDG(52:6) & -Pre 277.2, $\left[\mathrm{M}+\mathrm{C}_{2} \mathrm{H}_{3} \mathrm{O}_{2}\right]^{-}$ & 18:3-unox-acMGDG-1 \\
\hline 1014.6 & $\mathrm{C}_{61} \mathrm{H}_{106} \mathrm{O}_{11}$ & acMGDG(52:5) & -Pre 277.2, $\left[\mathrm{M}+\mathrm{C}_{2} \mathrm{H}_{3} \mathrm{O}_{2}\right]^{-}$ & 18:3-unox-acMGDG-1 \\
\hline 1034.6 & $\mathrm{C}_{63} \mathrm{H}_{102} \mathrm{O}_{11}$ & acMGDG(54:9) & -Pre 277.2, $\left[\mathrm{M}+\mathrm{C}_{2} \mathrm{H}_{3} \mathrm{O}_{2}\right]^{-}$ & 18:3-unox-acMGDG-1 \\
\hline 1036.6 & $\mathrm{C}_{63} \mathrm{H}_{104} \mathrm{O}_{11}$ & acMGDG(54:8) & -Pre 277.2, $\left[\mathrm{M}+\mathrm{C}_{2} \mathrm{H}_{3} \mathrm{O}_{2}\right]^{-}$ & 18:3-unox-acMGDG-1 \\
\hline 1038.6 & $\mathrm{C}_{63} \mathrm{H}_{106} \mathrm{O}_{11}$ & acMGDG(54:7) & -Pre 277.2, $\left[\mathrm{M}+\mathrm{C}_{2} \mathrm{H}_{3} \mathrm{O}_{2}\right]^{-}$ & 18:3-unox-acMGDG-1 \\
\hline 745.5 & $\mathrm{C}_{39} \mathrm{H}_{72} \mathrm{O}_{10} \mathrm{PN}$ & $\mathrm{PE}(34: 3-2 \mathrm{O})$ & -Pre 291.2, [M-H] & 18:4-O-ox-lipid-1 \\
\hline 756.5 & $\mathrm{C}_{40} \mathrm{H}_{69} \mathrm{O}_{11} \mathrm{P}$ & PG(34:5-O) & -Pre 291.2, [M - H] & 18:4-O-ox-lipid-1 \\
\hline 758.5 & $\mathrm{C}_{40} \mathrm{H}_{71} \mathrm{O}_{11} \mathrm{P}$ & $\mathrm{PG}(34: 4-\mathrm{O})$ & -Pre 291.2, [M - H] & 18:4-O-ox-lipid-1 \\
\hline 760.5 & $\mathrm{C}_{43} \mathrm{H}_{68} \mathrm{O}_{11}$ & MGDG(34:7-O) & -Pre 291.2, [M - H $]^{-}$ & 18:4-O-ox-lipid-1 \\
\hline 767.5 & $\mathrm{C}_{41} \mathrm{H}_{70} \mathrm{O}_{10} \mathrm{PN}$ & PE(36:6-2O) & -Pre 291.2, [M - H $]^{-}$ & 18:4-O-ox-lipid-1 \\
\hline 769.5 & $\mathrm{C}_{41} \mathrm{H}_{72} \mathrm{O}_{10} \mathrm{PN}$ & $\mathrm{PE}(36: 5-2 \mathrm{O})$ & -Pre 291.2, [M - H] & 18:4-O-ox-lipid-1 \\
\hline 774.5 & $\mathrm{C}_{43} \mathrm{H}_{66} \mathrm{O}_{12}$ & MGDG(34:8-2O) & -Pre 291.2, $\left[\mathrm{M}+\mathrm{C}_{2} \mathrm{H}_{3} \mathrm{O}_{2}\right]^{-}$ & 18:4-O-ox-lipid-1 \\
\hline 778.5 & $\mathrm{C}_{43} \mathrm{H}_{70} \mathrm{O}_{12}$ & MGDG(34:6-2O) & -Pre 291.2, $\left[\mathrm{M}+\mathrm{C}_{2} \mathrm{H}_{3} \mathrm{O}_{2}\right]^{-}$ & 18:4-O-ox-lipid-1 \\
\hline 787.5 & $\mathrm{C}_{42} \mathrm{H}_{78} \mathrm{O}_{10} \mathrm{PN}$ & $\mathrm{PC}(34: 3-2 \mathrm{O})$ & -Pre 291.2, $\left[\mathrm{M}+\mathrm{C}_{2} \mathrm{H}_{3} \mathrm{O}_{2}\right]^{-}$ & 18:4-O-ox-lipid-1 \\
\hline 788.5 & $\mathrm{C}_{45} \mathrm{H}_{72} \mathrm{O}_{11}$ & MGDG(36:7-O) & -Pre 291.2, [M - H] & 18:4-O-ox-lipid-1 \\
\hline 792.5 & $\mathrm{C}_{43} \mathrm{H}_{68} \mathrm{O}_{13}$ & MGDG(34:7-3O) & -Pre 291.2, $\left[\mathrm{M}+\mathrm{C}_{2} \mathrm{H}_{3} \mathrm{O}_{2}\right]^{-}$ & 18:4-O-ox-lipid-1 \\
\hline 802.5 & $\mathrm{C}_{45} \mathrm{H}_{70} \mathrm{O}_{12}$ & MGDG(36:8-2O) & -Pre 291.2, $\left[\mathrm{M}+\mathrm{C}_{2} \mathrm{H}_{3} \mathrm{O}_{2}\right]^{-}$ & 18:4-O-ox-lipid-1 \\
\hline 806.5 & $\mathrm{C}_{45} \mathrm{H}_{74} \mathrm{O}_{12}$ & MGDG(36:6-2O) & -Pre 291.2, $\left[\mathrm{M}+\mathrm{C}_{2} \mathrm{H}_{3} \mathrm{O}_{2}\right]^{-}$ & 18:4-O-ox-lipid-1 \\
\hline 809.5 & $\mathrm{C}_{44} \mathrm{H}_{76} \mathrm{O}_{10} \mathrm{PN}$ & $\mathrm{PC}(36: 6-2 \mathrm{O})$ & -Pre 291.2, $\left[\mathrm{M}+\mathrm{C}_{2} \mathrm{H}_{3} \mathrm{O}_{2}\right]^{-}$ & 18:4-O-ox-lipid-1 \\
\hline 811.5 & $\mathrm{C}_{4} \mathrm{H}_{78} \mathrm{O}_{10} \mathrm{PN}$ & $\mathrm{PC}(36: 5-2 \mathrm{O})$ & -Pre 291.2, $\left[\mathrm{M}+\mathrm{C}_{2} \mathrm{H}_{3} \mathrm{O}_{2}\right]^{-}$ & 18:4-O-ox-lipid-1 \\
\hline 820.5 & $\mathrm{C}_{45} \mathrm{H}_{72} \mathrm{O}_{13}$ & MGDG(36:7-3O) & -Pre 291.2, $\left[\mathrm{M}+\mathrm{C}_{2} \mathrm{H}_{3} \mathrm{O}_{2}\right]^{-}$ & 18:4-O-ox-lipid-1 \\
\hline 922.6 & $\mathrm{C}_{49} \mathrm{H}_{78} \mathrm{O}_{16}$ & DGDG(34:7-O) & -Pre 291.2, [M-H] & 18:4-O-ox-lipid-1 \\
\hline 928.6 & $\mathrm{C}_{49} \mathrm{H}_{84} \mathrm{O}_{16}$ & DGDG(34:4-O) & -Pre 291.2, $\left[\mathrm{M}+\mathrm{C}_{2} \mathrm{H}_{3} \mathrm{O}_{2}\right]^{-}$ & 18:4-O-ox-lipid-1 \\
\hline 936.6 & $\mathrm{C}_{49} \mathrm{H}_{76} \mathrm{O}_{17}$ & DGDG(34:8-2O) & -Pre 291.2, $\left[\mathrm{M}+\mathrm{C}_{2} \mathrm{H}_{3} \mathrm{O}_{2}\right]^{-}$ & 18:4-O-ox-lipid-1 \\
\hline 940.6 & $\mathrm{C}_{49} \mathrm{H}_{80} \mathrm{O}_{17}$ & DGDG(34:6-2O) & -Pre 291.2, $\left[\mathrm{M}+\mathrm{C}_{2} \mathrm{H}_{3} \mathrm{O}_{2}\right]^{-}$ & 18:4-O-ox-lipid-1 \\
\hline 946.6 & $\mathrm{C}_{49} \mathrm{H}_{86} \mathrm{O}_{17}$ & DGDG(34:3-2O) & -Pre 291.2, [M - H] & 18:4-O-ox-lipid-1 \\
\hline 950.6 & $\mathrm{C}_{51} \mathrm{H}_{82} \mathrm{O}_{16}$ & DGDG(36:7-O) & -Pre 291.2, $\left[\mathrm{M}+\mathrm{C}_{2} \mathrm{H}_{3} \mathrm{O}_{2}\right]^{-}$ & 18:4-O-ox-lipid-1 \\
\hline 954.6 & $\mathrm{C}_{49} \mathrm{H}_{78} \mathrm{O}_{18}$ & DGDG(34:7-3O) & -Pre 291.2, $\left[\mathrm{M}+\mathrm{C}_{2} \mathrm{H}_{3} \mathrm{O}_{2}\right]^{-}$ & 18:4-O-ox-lipid-1 \\
\hline 964.6 & $\mathrm{C}_{51} \mathrm{H}_{80} \mathrm{O}_{17}$ & DGDG(36:8-2O) & -Pre 291.2, $\left[\mathrm{M}+\mathrm{C}_{2} \mathrm{H}_{3} \mathrm{O}_{2}\right]^{-}$ & 18:4-O-ox-lipid-1 \\
\hline 968.6 & $\mathrm{C}_{51} \mathrm{H}_{84} \mathrm{O}_{17}$ & DGDG(36:6-2O) & -Pre 291.2, $\left[\mathrm{M}+\mathrm{C}_{2} \mathrm{H}_{3} \mathrm{O}_{2}\right]^{-}$ & 18:4-O-ox-lipid-1 \\
\hline 982.6 & $\mathrm{C}_{51} \mathrm{H}_{82} \mathrm{O}_{18}$ & DGDG(36:7-2O) & -Pre 291.2, $\left[\mathrm{M}+\mathrm{C}_{2} \mathrm{H}_{3} \mathrm{O}_{2}\right]^{-}$ & 18:4-O-ox-lipid-1 \\
\hline 992.6 & $\mathrm{C}_{59} \mathrm{H}_{92} \mathrm{O}_{12}$ & acMGDG(50:10-O) & -Pre 291.2, $\left[\mathrm{M}+\mathrm{C}_{2} \mathrm{H}_{3} \mathrm{O}_{2}\right]^{-}$ & 18:4-O-acMGDG-3 \\
\hline 998.6 & $\mathrm{C}_{59} \mathrm{H}_{98} \mathrm{O}_{12}$ & acMGDG(50:7-O) & -Pre 291.2, $\left[\mathrm{M}+\mathrm{C}_{2} \mathrm{H}_{3} \mathrm{O}_{2}\right]^{-}$ & 18:4-O-acMGDG-3 \\
\hline 1006.6 & $\mathrm{C}_{59} \mathrm{H}_{90} \mathrm{O}_{13}$ & acMGDG(50:11-2O) & -Pre 291.2, $\left[\mathrm{M}+\mathrm{C}_{2} \mathrm{H}_{3} \mathrm{O}_{2}\right]^{-}$ & 18:4-O-acMGDG-3 \\
\hline 1010.6 & $\mathrm{C}_{59} \mathrm{H}_{94} \mathrm{O}_{13}$ & acMGDG(50:7-2O) & -Pre 291.2, $\left[\mathrm{M}+\mathrm{C}_{2} \mathrm{H}_{3} \mathrm{O}_{2}\right]^{-}$ & 18:4-O-acMGDG-3 \\
\hline 1012.6 & $\mathrm{C}_{59} \mathrm{H}_{96} \mathrm{O}_{13}$ & acMGDG(50:8-2O) & -Pre 291.2, $\left[\mathrm{M}+\mathrm{C}_{2} \mathrm{H}_{3} \mathrm{O}_{2}\right]^{-}$ & 18:4-O-acMGDG-3 \\
\hline 1016.6 & $\mathrm{C}_{59} \mathrm{H}_{100} \mathrm{O}_{13}$ & acMGDG(50:6-2O) & -Pre 291.2, $\left[\mathrm{M}+\mathrm{C}_{2} \mathrm{H}_{3} \mathrm{O}_{2}\right]^{-}$ & 18:4-O-acMGDG-3 \\
\hline 1020.6 & $\mathrm{C}_{59} \mathrm{H}_{88} \mathrm{O}_{14}$ & acMGDG(50:12-3O), & -Pre 291.2, $\left[\mathrm{M}+\mathrm{C}_{2} \mathrm{H}_{3} \mathrm{O}_{2}\right]^{-}$ & 18:4-O-acMGDG-3 \\
\hline
\end{tabular}




\begin{tabular}{|c|c|c|c|c|}
\hline & $\mathrm{C}_{61} \mathrm{H}_{96} \mathrm{O}_{12}$ & acMGDG(52:10-O) & & \\
\hline 1024.6 & $\mathrm{C}_{59} \mathrm{H}_{92} \mathrm{O}_{14}$ & acMGDG(50:10-3O) & -Pre 291.2, $\left[\mathrm{M}+\mathrm{C}_{2} \mathrm{H}_{3} \mathrm{O}_{2}\right]^{-}$ & 18:4-O-acMGDG-3 \\
\hline 1026.6 & $\mathrm{C}_{61} \mathrm{H}_{102} \mathrm{O}_{12}$ & acMGDG(52:7-O) & -Pre 291.2, $\left[\mathrm{M}+\mathrm{C}_{2} \mathrm{H}_{3} \mathrm{O}_{2}\right]^{-}$ & 18:4-O-acMGDG-3 \\
\hline 1030.6 & $\mathrm{C}_{59} \mathrm{H}_{98} \mathrm{O}_{14}$ & acMGDG(50:7-3O) & -Pre 291.2, $\left[\mathrm{M}+\mathrm{C}_{2} \mathrm{H}_{3} \mathrm{O}_{2}\right]^{-}$ & 18:4-O-acMGDG-3 \\
\hline 1034.6 & $\mathrm{C}_{61} \mathrm{H}_{94} \mathrm{O}_{13}$ & acMGDG(52:11-2O) & -Pre 291.2, $\left[\mathrm{M}+\mathrm{C}_{2} \mathrm{H}_{3} \mathrm{O}_{2}\right]^{-}$ & 18:4-O-acMGDG-3 \\
\hline 1038.6 & $\mathrm{C}_{61} \mathrm{H}_{98} \mathrm{O}_{13}$ & acMGDG(52:9-2O) & -Pre 291.2, $\left[\mathrm{M}+\mathrm{C}_{2} \mathrm{H}_{3} \mathrm{O}_{2}\right]^{-}$ & 18:4-O-acMGDG-3 \\
\hline 1040.6 & $\mathrm{C}_{61} \mathrm{H}_{100} \mathrm{O}_{13}$ & acMGDG(52:8-2O) & -Pre 291.2, $\left[\mathrm{M}+\mathrm{C}_{2} \mathrm{H}_{3} \mathrm{O}_{2}\right]^{-}$ & 18:4-O-acMGDG-3 \\
\hline 1044.6 & $\mathrm{C}_{61} \mathrm{H}_{104} \mathrm{O}_{13}$ & acMGDG(52:6-2O) & -Pre 291.2, $\left[\mathrm{M}+\mathrm{C}_{2} \mathrm{H}_{3} \mathrm{O}_{2}\right]^{-}$ & 18:4-O-acMGDG-3 \\
\hline 1048.6 & $\begin{array}{l}\mathrm{C}_{61} \mathrm{H}_{92} \mathrm{O}_{14} \\
\mathrm{C}_{63} \mathrm{H}_{100} \mathrm{O}_{12} \\
\end{array}$ & $\begin{array}{c}\operatorname{acMGDG}(52: 12-3 \mathrm{O}) \text {, } \\
\operatorname{acMGDG}(54: 10-\mathrm{O})\end{array}$ & -Pre 291.2, $\left[\mathrm{M}+\mathrm{C}_{2} \mathrm{H}_{3} \mathrm{O}_{2}\right]^{-}$ & 18:4-O-acMGDG-3 \\
\hline 1052.7 & $\mathrm{C}_{61} \mathrm{H}_{96} \mathrm{O}_{14}$ & acMGDG(52:10-30) & -Pre 291.2, $\left[\mathrm{M}+\mathrm{C}_{2} \mathrm{H}_{3} \mathrm{O}_{2}\right]^{-}$ & 18:4-O-acMGDG-3 \\
\hline 1054.7 & $\mathrm{C}_{63} \mathrm{H}_{106} \mathrm{O}_{12}$ & acMGDG(54:7-O) & -Pre 291.2, $\left[\mathrm{M}+\mathrm{C}_{2} \mathrm{H}_{3} \mathrm{O}_{2}\right]^{-}$ & 18:4-O-acMGDG-3 \\
\hline 1058.7 & $\mathrm{C}_{61} \mathrm{H}_{102} \mathrm{O}_{14}$ & acMGDG(52:7-3O) & -Pre 291.2, $\left[\mathrm{M}+\mathrm{C}_{2} \mathrm{H}_{3} \mathrm{O}_{2}\right]^{-}$ & 18:4-O-acMGDG-3 \\
\hline 1062.7 & $\begin{array}{l}\mathrm{C}_{63} \mathrm{H}_{98} \mathrm{O}_{13} \\
\mathrm{C}_{61} \mathrm{H}_{90} \mathrm{O}_{15} \\
\end{array}$ & $\begin{array}{l}\operatorname{acMGDG}(54: 11-2 \mathrm{O}) \text {, } \\
\operatorname{acMGDG}(52: 13-4 \mathrm{O})\end{array}$ & -Pre 291.2, $\left[\mathrm{M}+\mathrm{C}_{2} \mathrm{H}_{3} \mathrm{O}_{2}\right]^{-}$ & 18:4-O-acMGDG-3 \\
\hline 1066.7 & $\begin{array}{l}\mathrm{C}_{61} \mathrm{H}_{94} \mathrm{O}_{15} \\
\mathrm{C}_{63} \mathrm{H}_{102} \mathrm{O}_{13}\end{array}$ & $\begin{array}{c}\text { acMGDG(52:11-4O), } \\
\operatorname{acMGDG}(54: 9-2 \mathrm{O})\end{array}$ & -Pre 291.2, $\left[\mathrm{M}+\mathrm{C}_{2} \mathrm{H}_{3} \mathrm{O}_{2}\right]^{-}$ & 18:4-O-acMGDG-3 \\
\hline 1068.7 & $\mathrm{C}_{63} \mathrm{H}_{104} \mathrm{O}_{13}$ & acMGDG(54:8-2O) & -Pre 291.2, $\left[\mathrm{M}+\mathrm{C}_{2} \mathrm{H}_{3} \mathrm{O}_{2}\right]^{-}$ & 18:4-O-acMGDG-3 \\
\hline 1070.7 & $\begin{array}{l}\mathrm{C}_{61} \mathrm{H}_{98} \mathrm{O}_{15} \\
\mathrm{C}_{63} \mathrm{H}_{106} \mathrm{O}_{13} \\
\end{array}$ & $\begin{array}{l}\operatorname{acMGDG}(52: 9-4 \mathrm{O}), \\
\operatorname{acMGDG}(54: 7-2 \mathrm{O})\end{array}$ & -Pre 291.2, $\left[\mathrm{M}+\mathrm{C}_{2} \mathrm{H}_{3} \mathrm{O}_{2}\right]^{-}$ & 18:4-O-acMGDG-3 \\
\hline 1072.7 & $\begin{array}{l}\mathrm{C}_{63} \mathrm{H}_{108} \mathrm{O}_{13} \\
\mathrm{C}_{61} \mathrm{H}_{100} \mathrm{O}_{15}\end{array}$ & $\begin{array}{l}\text { acMGDG(54:6-2O), } \\
\operatorname{acMGDG}(52: 8-4 \mathrm{O})\end{array}$ & -Pre 291.2, $\left[\mathrm{M}+\mathrm{C}_{2} \mathrm{H}_{3} \mathrm{O}_{2}\right]^{-}$ & 18:4-O-acMGDG-3 \\
\hline 1076.7 & $\mathrm{C}_{63} \mathrm{H}_{96} \mathrm{O}_{14}$ & $\operatorname{acMGDG}(54: 12-3 \mathrm{O})$ & -Pre 291.2, $\left[\mathrm{M}+\mathrm{C}_{2} \mathrm{H}_{3} \mathrm{O}_{2}\right]^{-}$ & 18:4-O-acMGDG-3 \\
\hline 1080.7 & $\mathrm{C}_{63} \mathrm{H}_{100} \mathrm{O}_{14}$ & acMGDG(54:10-3O) & -Pre 291.2, $\left[\mathrm{M}+\mathrm{C}_{2} \mathrm{H}_{3} \mathrm{O}_{2}\right]^{-}$ & 18:4-O-acMGDG-3 \\
\hline 1084.7 & $\mathrm{C}_{61} \mathrm{H}_{96} \mathrm{O}_{16}$ & acMGDG(52:10-5O) & -Pre 291.2, $\left[\mathrm{M}+\mathrm{C}_{2} \mathrm{H}_{3} \mathrm{O}_{2}\right]^{-}$ & 18:4-O-acMGDG-3 \\
\hline 1086.7 & $\mathrm{C}_{63} \mathrm{H}_{106} \mathrm{O}_{14}$ & acMGDG(54:7-3O) & -Pre 291.2, $\left[\mathrm{M}+\mathrm{C}_{2} \mathrm{H}_{3} \mathrm{O}_{2}\right]^{-}$ & 18:4-O-acMGDG-3 \\
\hline 729.5 & $\mathrm{C}_{39} \mathrm{H}_{72} \mathrm{O}_{9} \mathrm{PN}$ & $\mathrm{PE}(34: 3-\mathrm{O})$ & -Pre 293.2, [M-H] & 18:3-O-ox-lipid-1 \\
\hline 747.5 & $\mathrm{C}_{39} \mathrm{H}_{74} \mathrm{O}_{10} \mathrm{PN}$ & $\mathrm{PE}(34: 2-2 \mathrm{O})$ & -Pre 293.2, [M-H] & 18:3-O-ox-lipid-1 \\
\hline 751.5 & $\mathrm{C}_{41} \mathrm{H}_{70} \mathrm{O}_{9} \mathrm{PN}$ & $\mathrm{PE}(36: 6-\mathrm{O})$ & -Pre 293.2, [M - H $]^{-}$ & 18:3-O-ox-lipid-1 \\
\hline 753.5 & $\mathrm{C}_{41} \mathrm{H}_{72} \mathrm{O}_{9} \mathrm{PN}$ & $\mathrm{PE}(36: 5-\mathrm{O})$ & -Pre 293.2, [M - H $]^{-}$ & 18:3-O-ox-lipid-1 \\
\hline 758.5 & $\mathrm{C}_{40} \mathrm{H}_{71} \mathrm{O}_{11} \mathrm{P}$ & PG(34:4-O) & -Pre 293.2, [M - H $]^{-}$ & 18:3-O-ox-lipid-1 \\
\hline 760.5 & $\mathrm{C}_{40} \mathrm{H}_{73} \mathrm{O}_{11} \mathrm{P}$ & $\mathrm{PG}(34: 3-\mathrm{O})$ & -Pre 293.2, [M - H $]^{-}$ & 18:3-O-ox-lipid-1 \\
\hline 762.5 & $\mathrm{C}_{43} \mathrm{H}_{70} \mathrm{O}_{11}$ & MGDG(34:6-O) & -Pre 293.2, $\left[\mathrm{M}+\mathrm{C}_{2} \mathrm{H}_{3} \mathrm{O}_{2}\right]^{-}$ & 18:3-O-ox-lipid-1 \\
\hline 769.5 & $\mathrm{C}_{41} \mathrm{H}_{72} \mathrm{O}_{10} \mathrm{PN}$ & $\mathrm{PE}(36: 5-2 \mathrm{O})$ & -Pre 293.2, $[\mathrm{M}-\mathrm{H}]^{-}$ & 18:3-O-ox-lipid-1 \\
\hline 771.5 & $\mathrm{C}_{41} \mathrm{H}_{74} \mathrm{O}_{10} \mathrm{PN}$ & $\mathrm{PE}(36: 4-2 \mathrm{O})$ & -Pre 293.2, [M - H] & 18:3-O-ox-lipid-1 \\
\hline 771.5 & $\mathrm{C}_{42} \mathrm{H}_{78} \mathrm{O}_{9} \mathrm{PN}$ & $\mathrm{PC}(34: 3-\mathrm{O})$ & -Pre 293.2, $\left[\mathrm{M}+\mathrm{C}_{2} \mathrm{H}_{3} \mathrm{O}_{2}\right]^{-}$ & 18:3-O-ox-lipid-1 \\
\hline 776.5 & $\mathrm{C}_{40} \mathrm{H}_{73} \mathrm{O}_{12} \mathrm{P}$ & $\mathrm{PG}(34: 3-2 \mathrm{O})$ & -Pre 293.2, [M - H $]^{-}$ & 18:3-O-ox-lipid-1 \\
\hline 776.5 & $\mathrm{C}_{43} \mathrm{H}_{68} \mathrm{O}_{12}$ & MGDG(34:7-2O) & -Pre 293.2, $\left[\mathrm{M}+\mathrm{C}_{2} \mathrm{H}_{3} \mathrm{O}_{2}\right]^{-}$ & 18:3-O-ox-lipid-1 \\
\hline 778.5 & $\mathrm{C}_{40} \mathrm{H}_{75} \mathrm{O}_{12} \mathrm{P}$ & $\mathrm{PG}(34: 2-2 \mathrm{O})$ & -Pre 293.2, [M - H] & 18:3-O-ox-lipid-1 \\
\hline 789.5 & $\mathrm{C}_{42} \mathrm{H}_{80} \mathrm{O}_{10} \mathrm{PN}$ & $\mathrm{PC}(34: 2-2 \mathrm{O})$ & -Pre 293.2, $\left[\mathrm{M}+\mathrm{C}_{2} \mathrm{H}_{3} \mathrm{O}_{2}\right]^{-}$ & 18:3-O-ox-lipid-1 \\
\hline 790.5 & $\mathrm{C}_{45} \mathrm{H}_{74} \mathrm{O}_{11}$ & MGDG(36:6-O) & -Pre 293.2, [M - H $]^{-}$ & 18:3-O-ox-lipid-1 \\
\hline 793.5 & $\mathrm{C}_{44} \mathrm{H}_{76} \mathrm{O}_{9} \mathrm{PN}$ & $\mathrm{PC}(36: 6-\mathrm{O})$ & -Pre 293.2, $\left[\mathrm{M}+\mathrm{C}_{2} \mathrm{H}_{3} \mathrm{O}_{2}\right]^{-}$ & 18:3-O-ox-lipid-1 \\
\hline 795.5 & $\mathrm{C}_{44} \mathrm{H}_{78} \mathrm{O}_{9} \mathrm{PN}$ & $\mathrm{PC}(36: 5-\mathrm{O})$ & -Pre 293.2, $\left[\mathrm{M}+\mathrm{C}_{2} \mathrm{H}_{3} \mathrm{O}_{2}\right]^{-}$ & 18:3-O-ox-lipid-1 \\
\hline 804.5 & $\mathrm{C}_{45} \mathrm{H}_{72} \mathrm{O}_{12}$ & MGDG(36:7-2O) & -Pre 293.2, $\left[\mathrm{M}+\mathrm{C}_{2} \mathrm{H}_{3} \mathrm{O}_{2}\right]^{-}$ & 18:3-O-ox-lipid-1 \\
\hline 811.5 & $\mathrm{C}_{44} \mathrm{H}_{78} \mathrm{O}_{10} \mathrm{PN}$ & $\mathrm{PC}(36: 5-2 \mathrm{O})$ & -Pre 293.2, $\left[\mathrm{M}+\mathrm{C}_{2} \mathrm{H}_{3} \mathrm{O}_{2}\right]^{-}$ & 18:3-O-ox-lipid-1 \\
\hline
\end{tabular}




\begin{tabular}{|c|c|c|c|c|}
\hline 813.5 & $\mathrm{C}_{44} \mathrm{H}_{80} \mathrm{O}_{10} \mathrm{PN}$ & $\mathrm{PC}(36: 4-2 \mathrm{O})$ & -Pre 293.2, $\left[\mathrm{M}+\mathrm{C}_{2} \mathrm{H}_{3} \mathrm{O}_{2}\right]^{-}$ & 18:3-O-ox-lipid-1 \\
\hline 924.6 & $\mathrm{C}_{49} \mathrm{H}_{80} \mathrm{O}_{16}$ & DGDG(34:6-O) & -Pre 293.2, $\left[\mathrm{M}+\mathrm{C}_{2} \mathrm{H}_{3} \mathrm{O}_{2}\right]^{-}$ & 18:3-O-ox-lipid-1 \\
\hline 930.6 & $\mathrm{C}_{49} \mathrm{H}_{86} \mathrm{O}_{16}$ & DGDG(34:3-O) & -Pre 293.2, $\left[\mathrm{M}+\mathrm{C}_{2} \mathrm{H}_{3} \mathrm{O}_{2}\right]^{-}$ & 18:3-O-ox-lipid-1 \\
\hline 938.6 & $\mathrm{C}_{49} \mathrm{H}_{78} \mathrm{O}_{17}$ & DGDG(34:7-2O) & -Pre 293.2, $\left[\mathrm{M}+\mathrm{C}_{2} \mathrm{H}_{3} \mathrm{O}_{2}\right]^{-}$ & 18:3-O-ox-lipid-1 \\
\hline 952.6 & $\mathrm{C}_{51} \mathrm{H}_{8} \mathrm{O}_{16}$ & DGDG(36:6-O) & -Pre 293.2, [M + $\left.\mathrm{C}_{2} \mathrm{H}_{3} \mathrm{O}_{2}\right]^{-}$ & 18:3-O-ox-lipid-1 \\
\hline 966.6 & $\mathrm{C}_{51} \mathrm{H}_{82} \mathrm{O}_{17}$ & DGDG(36:7-2O) & -Pre 293.2, $\left[\mathrm{M}+\mathrm{C}_{2} \mathrm{H}_{3} \mathrm{O}_{2}\right]^{-}$ & 18:3-O-ox-lipid-1 \\
\hline 731.5 & $\mathrm{C}_{39} \mathrm{H}_{74} \mathrm{O}_{9} \mathrm{PN}$ & $\mathrm{PE}(36: 2-\mathrm{O})$ & -Pre 295.2, [M - H $]^{-}$ & 18:2-O-ox-lipid-1 \\
\hline 753.5 & $\mathrm{C}_{41} \mathrm{H}_{2} \mathrm{O}_{9} \mathrm{PN}$ & $\mathrm{PE}(36: 5-\mathrm{O})$ & -Pre 295.2, [M - H] & 18:2-O-ox-lipid-1 \\
\hline 755.5 & $\mathrm{C}_{41} \mathrm{H}_{74} \mathrm{O}_{9} \mathrm{PN}$ & $\mathrm{PE}(36: 4-\mathrm{O})$ & -Pre 295.2, [M - H] & 18:2-O-ox-lipid-1 \\
\hline 760.5 & $\mathrm{C}_{40} \mathrm{H}_{73} \mathrm{O}_{11} \mathrm{P}$ & PG(34:3-O) & -Pre 295.2, [M - H] & 18:2-O-ox-lipid-1 \\
\hline 762.5 & $\mathrm{C}_{40} \mathrm{H}_{75} \mathrm{O}_{11} \mathrm{P}$ & PG(34:2-O) & -Pre 295.2, [M - H] & 18:2-O-ox-lipid-1 \\
\hline 773.5 & $\mathrm{C}_{42} \mathrm{H}_{80} \mathrm{O}_{9} \mathrm{PN}$ & $\mathrm{PC}(34: 2-\mathrm{O})$ & -Pre 295.2, $\left[\mathrm{M}+\mathrm{C}_{2} \mathrm{H}_{3} \mathrm{O}_{2}\right]^{-}$ & 18:2-O-ox-lipid-1 \\
\hline 795.5 & $\mathrm{C}_{44} \mathrm{H}_{78} \mathrm{O}_{9} \mathrm{PN}$ & $\mathrm{PC}(36: 5-\mathrm{O})$ & -Pre 295.2, $\left[\mathrm{M}+\mathrm{C}_{2} \mathrm{H}_{3} \mathrm{O}_{2}\right]^{-}$ & 18:2-O-ox-lipid-1 \\
\hline 797.5 & $\mathrm{C}_{44} \mathrm{H}_{80} \mathrm{O}_{9} \mathrm{PN}$ & PC(36:4-O) & -Pre 295.2, $\left[\mathrm{M}+\mathrm{C}_{2} \mathrm{H}_{3} \mathrm{O}_{2}\right]^{-}$ & 18:2-O-ox-lipid-1 \\
\hline
\end{tabular}




\section{References}

1. Gilmour S. J., Hajela R. K., and Thomashow M. F. (1988) Cold acclimation in Arabidopsis thaliana. Plant Physiol. 87, 745-750.

2. Uemura M., Joseph R. A., and Steponkus P. L. (1995) Cold acclimation of Arabidopsis thaliana (Effect on plasma membrane lipid composition and freeze-induced lesions). Plant Physiol. 109, 1530.

3. Welti R., Li W., Li M., Sang Y., Biesiada H., Zhou H. E., Rajashekar C. B., Williams T. D., and Wang X. (2002) Profiling membrane lipids in plant stress responses. Role of phospholipase D $\alpha$ in freezinginduced lipid changes in Arabidopsis. J. Biol. Chem. 277, 31994-32002.

4. Li W., Wang R., Li M., Li L., Wang C., Welti R., and Wang X. (2008) Differential degradation of extraplastidic and plastidic lipids during freezing and post-freezing recovery in Arabidopsis thaliana. J. Biol. Chem. 283, 461-468.

5. Degenkolbe T., Giavalisco P., Zuther E., Seiwert B., Hincha D. K., and Willmitzer L. (2012) Differential remodeling of the lipidome during cold acclimation in natural accessions of Arabidopsis thaliana. Plant J. 72, 972-982.

6. Chen M., and Thelen J. J. (2013) ACYL-LIPID DESATURASE2 is required for chilling and freezing tolerance in Arabidopsis. Plant Cell 25, 1430-1444.

7. Routaboul J. M., Fischer S. F., and Browse J. (2000) Trienoic fatty acids are required to maintain chloroplast function at low temperatures. Plant Physiol. 124, 1697-1705.

8. Moellering E. R., Muthan B., and Benning C. (2010) Freezing tolerance in plants requires lipid remodeling at the outer chloroplast membrane. Science 330, 226-228. 
9. Takami T., Shibata M., Kobayashi Y., and Shikanai T. (2010)_De novo biosynthesis of fatty acids plays critical roles in the response of the photosynthetic machinery to low temperature in Arabidopsis. Plant Cell Physiol. 51, 1265-1275.

10. Li W., Li M., Zhang W., Welti R., and Wang X. (2004) The plasma membrane-bound PHOSPHOLIPASE D $\delta$ enhances freezing tolerance in Arabidopsis thaliana. Nat. Biotechnol. 22, 427-433.

11. Chen Q. F., Xiao S., and Chye M. L. (2008) Overexpression of the Arabidopsis 10-kilodalton acylcoenzyme A-binding protein ACBP6 enhances freezing tolerance. Plant Physiol. 148, 304-315.

12. Burgos A., Szymanski J., Seiwert B., Degenkolbe T., Hannah M. A., Giavalisco P., and Willmitzer L. (2011) Analysis of short-term changes in the Arabidopsis thaliana glycerolipidome in response to temperature and light. Plant J. 66, 656-668.

13. Vu H. S., Tamura P., Galeva N. A., Chaturvedi R., Roth M. R., Williams T. D., Wang X., Shah J., and Welti R. (2012) Direct infusion mass spectrometry of oxylipin-containing Arabidopsis membrane lipids reveals varied patterns in different stress responses. Plant Physiol. 158, 324-339.

14. Shiva S., Vu H. S., Roth M. R., Zhou Z., Marepally S. R., Nune D. S., Lushington G. H., Visvanathan M., and Welti R. (2013) Lipidomic analysis of plant membrane lipids by direct infusion tandem mass spectrometry. Methods Mol. Biol. 1009, 79-91.

15. Zhou Z., Marepally S. R., Nune D. S., Pallakollu P., Ragan G., Roth M. R., Wang L., Lushington G. H., Visvanathan M., and Welti R. (2011) LipidomeDB Data Calculation Environment: Online processing of direct-infusion mass spectral data for lipid profiles. Lipids $46,879-884$.

16. Bligh E. G., and Dyer W. J. (1959) A rapid method of total lipid extraction and purification. Can. J. Biochem. Physiol. 37, 911-917. 
17. Ames B. N. (1966) Assay of inorganic phosphate, total phosphate and phosphatases. In: Methods Enzymol., Vol. VIII: Complex Carbohydrates. E. Neufeld and V. Ginsburg, eds. (Academic Press, New York, NY), pp. 115-118. 